\title{
The Design of English Autonomous Learning System Based on Web
}

\author{
JIN Yanjie 1, a \\ ${ }^{1}$ Jilin Business and Technology College, Changchun 130507, China \\ ajinyanjie@yeah.net
}

Keywords: English Autonomous Learning; Web; B/S; ADO.Net

\begin{abstract}
With the social life of informatization and economic globalization, the importance of learning English is becoming more and more prominent. As an important information carrier, English has become the most widely used in various fields of human life language. Web-based English autonomous learning is conducive to the improvement of English ability. This paper analysis and research the self-help English learning system based on web, it introduces the system requirements analysis and function are introduced. Based on the system database, it designed the relevant theoretical knowledge and combining with database design steps, completed the database design of this system, which mainly adopts B/S structure. To realize the centralized management of the teaching information, highly decentralized operation and information are sharing. At the same time, the traditional teaching management towards digital, intelligent, paperless and integrated direction.
\end{abstract}

\section{Introduction}

With the advent of the era of economic globalization, trade, information and cultural exchanges become a guarantee of the development of various countries. In line with the world in the process of language communication is essential, and English as a basic language of communication between with other countries, has become our basic tool into the international world. How to improve the effectiveness of English education and teaching, promote the development of learners' effective learning has been the concern of the scholars, but with the arrival of learning society, the researchers also pay more attention to the study of learners' autonomous learning ability [1]. Computer network, multimedia technology, the rapid development of communication technology and its wide application in the field of education, for autonomous learning activity development provides a strong support, some technology has been applied in English teaching and learning is based on web is a new means of access to knowledge is now a new way of English learning, and is playing a more and more important role [2].

English autonomous learning system based on Web mainly is to use information technology to solve the existing in network teaching environment can't timely emotional communication between teachers and students, the cultivation of the students' ability to practice and teaching resources, etc. To apply this system under the network teaching environment, in the true sense to realization between educator and educate are not restricted by time and space in the teaching, more abundant teaching resources for the use of educators and the educated, and the teaching form is given priority to autonomous learning. This paper analysis and research the English autonomous learning system based on Web, for the improvement of English learning efficiency and the quality and the cultivation of the ability, autonomic learning provides an effective way.

\section{System related key technologies}

$\mathrm{B} / \mathrm{S}$ is called the Browser/Server or Browser/Server mode. Three layer architecture of B/S consists of database, Web service layer and the browser of three parts. In B/S structure is mainly by the browser by sending a request to a Web service layer and Web service layer after the transaction will request sent to the backend database, background database on the requested data in the data processing, then the processed data of concrete on the Web server to resend it to the browser display [3]. B/S three-tier architecture system is shown in figure 1. 


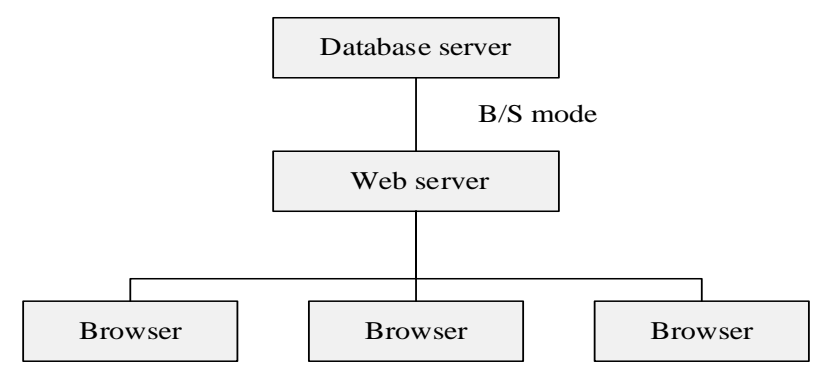

Figure 1. System structure of B/S

With the rapid development of science and technology, the enormous increase the network information, the requirement of increasing the user access speed of the web site, making the database access technology pays close attention to by more customers look forward to working with more and more, in the process of database link and access technology, database access technology of ADO.Net by more and more to the enterprise and the customers trust and praise [4]. The ADO.Net data access technology architecture is shown in figure 2.

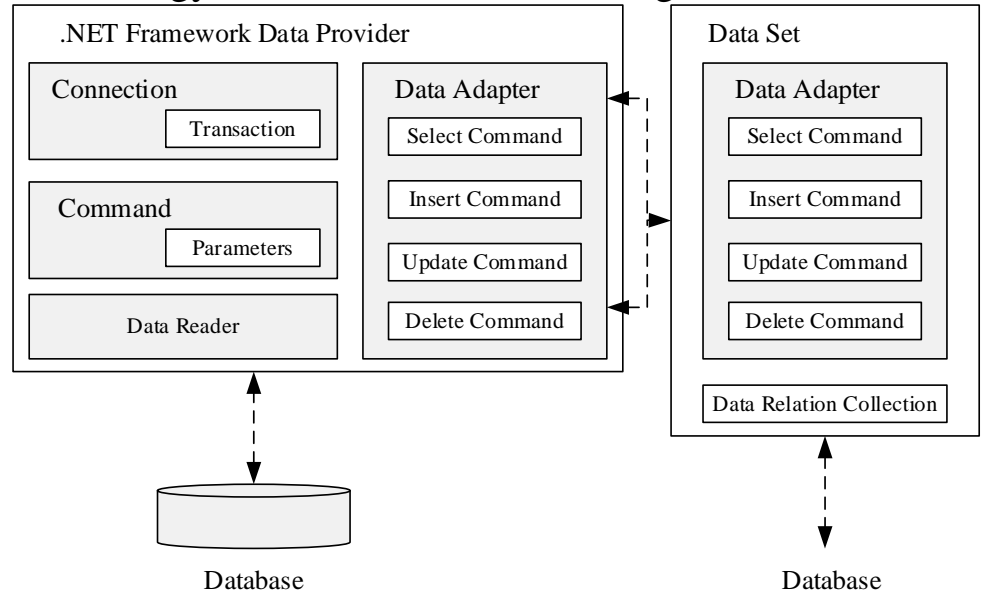

Figure 2. System structure of ADO.Net

\section{Functional requirements of Self-help web-based English learning system}

Software requirements analysis according to the theory of knowledge, combined with the actual needs of the system development, web-based English teaching website design mainly has five subsystems, namely the teaching projects, characteristic, grade examination, self-test, online communication platform [5]. Figure 3 is a web-based English self-service function module chart of the learning system.

Teaching project subsystem. Self-help web-based English learning system of network teaching module is by teachers' teaching contents, the extended practice links and related knowledge, teachers teaching goal, the relevant background knowledge, learning methods and audio-visual materials, is for the sake of those who didn't listen to the teacher carefully in class and foundation weak students again to study knowledge, so as to improve the students' ability of autonomous learning.

Specials subsystem. News topic includes pictures and audio-visual news are excerpts from the domestic and foreign famous news sites and news reports, and provide news related background knowledge and related words, etc.

Grade examination subsystem. AB mainly contains from listening, vocabulary, reading and study the topic of $A B$ counselling and $A B$ calendar year's exam and simulation. Mainly from the band 4 and band 6 listening, vocabulary, reading and study topic of counseling and allocation of the calendar year of CET exam and simulation.

Online self-test subsystem. According to the course of chapters and sections of various grade examination, as well as comprehensive chapters give students self-test platform chapters self-test, comprehensive level of self-test and self-test. Simulated test of self-test to get to know the degree of master. 
Communication platform subsystem. Through chat rooms, BBS, message boards and E-mail such as platform, can be achieved with interactive learning between teachers and students.

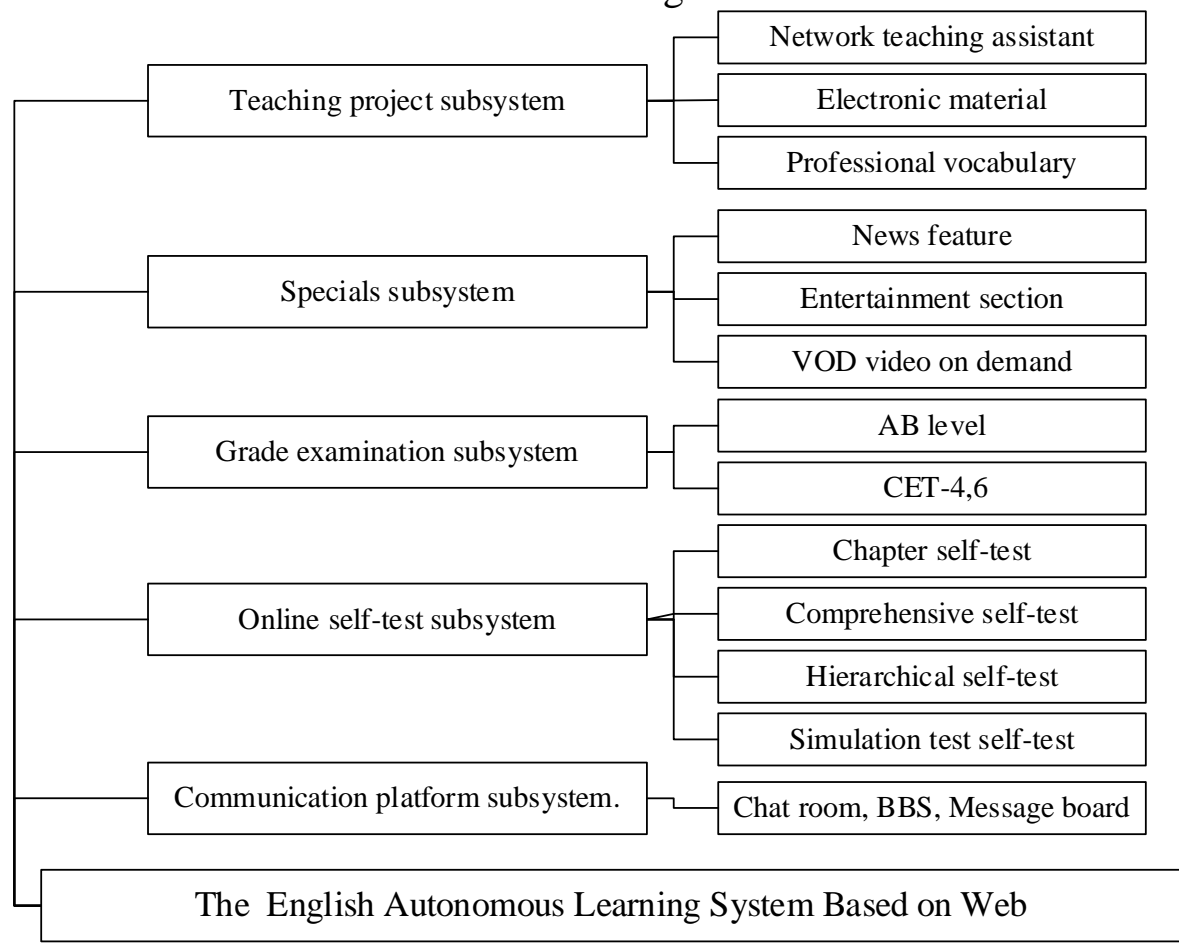

Figure 3. Function modules of the English autonomous learning system based on Web

\section{Overall design for the English autonomous learning system based on Web}

The basic design requirements of the English autonomous learning system based on Web mainly includes teaching projects, characteristic, grade examination, online self-test and communication platform modules. The teaching assistant project is mainly used in English teaching workers to share the corresponding electronic materials, PPT, and shared with draw lessons from aspects such as teaching design; Specials module is mainly used to this website and of contemporary social affairs, at the same time with entertainment modules and VOD video on demand to attract the interest of English learners to further study English; Rank test module is mainly used for different levels of students obtain corresponding level certificate; Online testing from chapter, comprehensive self-test, and simulation test paper self-test, etc., to assist in the graded English test; Communication platform is mainly a chat room and BBS and teachers, students' learning communication in time, to enhance the interest of learning English. English learning system architecture diagram as shown in figure 4.

The English autonomous learning system based on Web adopts B/S mode structure, the database is the key to the whole system design. English self-learning system based on Web system architecture mainly includes three aspects:

First, the data information center. It is the core part of the database of the whole system, the data are mainly from about self-help data in study English in higher vocational college.

Second, the server program module. The main module is running on the university campus network database server, the server side program module can have college information center to manage and maintain (mainly ACTS as the identity of the administrator), can be operation for data upload and modify.

Third, the client module. Client module mainly run in teaching projects, characteristic, grade examination, online self-test module and communication platform, different users into the system, can according to its access to this system for the corresponding operation. Self-help web-based 


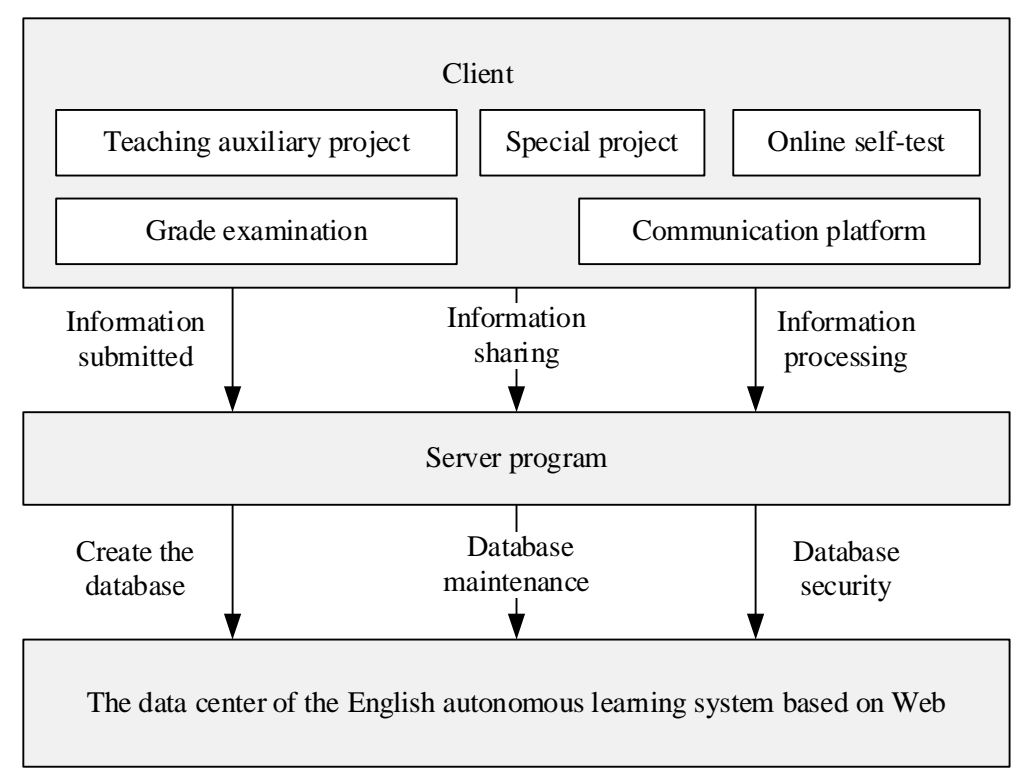

Figure 4.Overall structure of the English autonomous learning system based on Web

\section{Conclusion}

With the rapid development of information technology, online learning has become another way of learners to acquire knowledge. Network can provide learners with learning anytime and anywhere, to arouse learners' interest in learning, improve learning effect, and an important means of constructing a learning society in China. In this article, the status quo of network learning platform at home and abroad were analyzed, and it summarizes the existing problems, and put forward the research target of this article. It explores the guidance in the process of the design and implementation of theory for the web-based college English autonomous learning platform; On this basis, combining with the characteristics of college English and the actual need, it put forward the he overall design thought of English autonomous learning platform based on web.

\section{Acknowledgements}

Jilin province education science "twelfth five-year" plan: newly built undergraduate course colleges and universities English specialized graduation thesis, the research and practice of teaching and guidance work; Number: GH14481.

\section{References}

[1] C. Olston, and M. Najork: Foundations and Trends in Information Retrieval, Vol. 4(2010) No.3, p.175.

[2] M. Thelwall: Journal of Information Science, Vol. 27(2001) No.5, p. 319.

[3] H. Liu, J. Janssen, and E. Milios: Data \& Knowledge Engineering, Vol. 59(2006) No.2, p. 270.

[4] C. Bizer, J. Lehmann, and G. Kobilarov: Web Semantics: science, services and agents on the world wide web, Vol. 7(2009) No.3, p. 154.

[5] J.K. Batcheller, F. Reitsma: Computers, Environment and Urban Systems, Vol. 34(2010) 